\title{
STUDI KARAKTERISTIK MINYAK NILAM SEBAGAI ALTERNATIF PENGGANTI MINYAK TRANSFORMATOR
}

\author{
Jumardin $^{1}$, Jumiati Ilham ${ }^{2}$, Sardi Salim ${ }^{3}$ \\ ${ }^{123}$ Prodi Teknik Elektro, Fakultas Teknik, Universitas Negeri Gorontalo \\ Jl. Jend. Sudirman No.6 Kota Gorontalo 96128 Indonesia \\ Email : jumardin958@gmail.com, jumiatiilham@ung.ac.id, sardi@ung.ac.id
}

\begin{abstract}
Abstrak
Isolasi minyak umumnya menggunakan minyak mineral karena memiliki penyerapan panas yang baik dan karakteristik dielektrik sebagai isolator. Karena minyak mineralnya yang semakin lama semakin berkurang dan kurang ramah lingkungan, sangat penting mencari solusi untuk mengatasinya. Penelitian ini bertujuan untuk mengetahui karakteristik minyak nilam sebagai alternatif pengganti minyak Transformator. Penelitian ini menggunakan beberapa macam pengujian diantaranya kadar asam, kadar air, viskositas dan mengetahui pengaruh tegangan tembus. Hasil pengujian tegangan tembus minyak nilam belum memenuhi standar sebagai alternatif pengganti minyak transformator di mana tegangan tembus dengan menggunakan elektroda stengah bola yakni 15, $89 \mathrm{kV}$. Selanjutnya hasil pengujian kadar asam, kadar air dan viskositas ditemukan bahwa nilai pengujian kadar asam 35,344 mg/kg, kadar air $58.596 \mathrm{mg} / \mathrm{kg}$ dan viskositas 33. 16 cst. syarat minyak transformator harus memenuhi standar SPLN 49- 1: 1982 dan IEC 60296-2003. Dalam penelitian ini minyak nilam belum memenuhi memenuhi standar IEC 60296-2003. SPLN 49-1:
\end{abstract}

kata kunci: minyak nilam, minyak transformator

\section{Pendahuluan}

Transformator merupakan suatu alat listrik yang dapat menaikan dan menurunkan tegangan listrik. Pada transformator tersebut terdapat dua bagian yang sangat penting yakni inti besi dan kumparan. Inti besi berfungsi untuk mempermudah jalan fluks yang yang timbul akibat adanya arus listrik dalam belitan, Bahan inti ini terbuat dari lempengan - lempengan baja tipis agar dapat mengurangi panas( rugi - rugi besi) yang di akibatkan oleh arus. Selanjutnya kumparan transformator merupakan lilitan kawat berisolasi yang membentuk kumparan. Kumparan kumparan pada transformator ini terbagi 2 (dua) yaitu kumparan primer dan kumparan sekunder. Jika kumparan primer di hubungkan dengan tegangan/arus bolak balik maka pada kumparan tersebut timbul fluks yang menimbulkan induksi tegangan jika rangkaian sekunder di tutup, maka arus akan mengalir pada kumparan tersebut.Salah satu bagian penting dari transformator adalah minyak transformator. Minyak transformator merupakan salah satu bahan isolasi cair yang dipergunakan sebagai isolasi dan pendingin pada transformator, dimana ada dua bagian yang secara aktif membangkitkan panas yaitu kumparan (tembaga) dan inti (besi), minyak isolasi pada transformator berfungsi sebagai 
bahan pendingin yang menyalurkan panas ke sirip-sirip transformator serta sebagai pemadam busur api apabila terjadi percikan-percikan dalam belitan transformator. Berdasarkan bahan pembuatannya, minyak isolasi transformator terbagi atas dua jenis yaitu minyak isolasi dari olahan minyak bumi dan minyak isolasi yang berasal dari tumbuh-tumbuhan atau disebut minyak nabati (minyak organik).

Saat ini bahan yang di gunakan sebagai bahan isolasi cair pada Transformator menggunakan Minyak Bumi, hal ini di karenakan daya serap dan daya isolasinya sangat baik sebagai bahan isolasi transformator,akan tetapi, bahan dasar minyak bumi ini lama kelamaan akan habis karena tidak dapat di perbaharui. Salah satu bahan alternatif pengganti isolasi cair pada transformator adalah isolasi cair yang berasal dari tumbuh - tumbuhan atau minyak nabati. Diantaranya minyak kelapa, minyak zaitun dan minyak jarak yang telah dilakukan pengujian pada laboratorium sebagai minyak alternatif pengganti minyak isolasi Transformator.

Minyak nilam merupakan salah satu jenis minyak nabati yang berasal dari tanaman patchouli saat ini telah banyak dibudidayakan di indonesia dan merupakan bahan utama campuran produk- produk kosmetik, industri makanan, obat obatan serta sebagai kebutuhan industri lainya, sehingganya minyak nilam ini perlu di lakukan pengujian laboratorium tegangan tinggi maupun kimia sebagai alternatif pengganti minyak Transformator.

\section{TINJAUAN PUSTAKA}

\section{Minyak Transformator}

Minyak transformator adalah minyak mineral yang diperoleh dengan pemurnian minyak mentah. Sebagai bahan isolasi, minyak transformator harus mempunyai tegangan tembus yang tinggi. Selain itu minyak ini berfungsi sebagai media pendingin yaitu untuk mengantisipasi kenaikan temperatur (suhu) pada transformator, adanya kenaikan temperatur yang terlalu tinggi bisa merusak isolasi kertas pada gulungan (coil) di dalam transformator, dan suhu yang terlalu panas sehingga dapat menurunkan tahanan isolasi yang dapat mengakibatkan hubung singkat antara phasa dengan phasa dan phasa dengan body di dalam transformator sehingga dapat menimbulkan kerusakan pada transformator.Sedangkan fungsi minyak sebagai media isolasi adalah merupakan sesuatu yang mutlak untuk menghindari terjadinya short circuit atau hubung singkat di dalam transformator baik antara phasa maupun sisi phasa 
dengan body, dimana hubung singkat tersebut akan mengakibatkan transformator meledak.

Berikut adalah Tabel Spesifikasi Minyak Transformator Menurut IEC 60296-2003

\begin{tabular}{|c|c|c|}
\hline $\mathrm{N}_{0}$ & Parameter Cji & Batasan \\
\hline 1 & $V^{\prime}$ iskositas $40^{\circ} \mathrm{C}$ & Max $12 \mathrm{cSt}$ \\
\hline 2 & Titik Tuang & $\operatorname{Max}-40^{\circ} \mathrm{C}$ \\
\hline 3 & Kadar Air & Max $30 \mathrm{mg} k g$ \\
\hline 4 & $\begin{array}{l}\text { Tegangan Tembus } \\
\text { - Sebelum Treatment } \\
\text { - Setelah Treatment }\end{array}$ & $\begin{array}{l}\text { Min. } 30 \mathrm{kV} / 2,5 \mathrm{~mm} \\
\text { Min. } 70 \mathrm{kV} / 2,5\end{array}$ \\
\hline 5 & Densitas Pada $20^{\circ} \mathrm{C}$ & $\operatorname{Max} 0,895 \mathrm{gml}$ \\
\hline 6 & Kenetralan (Keasaman) & Max $0,01 \mathrm{mgKOH} / \mathrm{kg}$ \\
\hline
\end{tabular}

\section{Jenis - jenis minyak isolasi}

\section{Minyak Organik}

Kelompok minyak organik meliputi minyak sayur, minyak damar, dan ester. Jenis minyak ini mulai banyak dipakai sebagai bahan isolasi pada akhir abad ke19, terlebih dengan semakin menipisnya cadangan mineral tak terbaharukan dan masih kecilnya pemakaian minyak sintetik membuat minyak organik mendapatkan perhatian lebih.

\section{Minyak mineral}

Minyak isolasi mineral adalah minyak isolasi yang bahan dasarnya berasal dari minyak bumi yang diproses dengan cara destilasi. Minyak isolasi hasil destilasi ini harus mengalami beberapa proses lagi agar diperoleh tahanan isolasi yang tinggi, stabilitas panas yang baik, mempunyai karakteristik panas yang stabil, dan memenuhi syarat-syarat teknis yang lain. Minyak isolasi mineral banyak digunakan pada transformator daya, kabel, pemutus daya (CB) dan kapasitor.

\section{Minyak sintesis}

Minyak isolasi sintetis adalah minyak isolasi yang diolah dengan proses kimia untuk mendapatkan karakteristik yang lebih baik. Sifat - sifat penting dari minyak isolasi sintetis bila dibandingkan dengan minyak isolasi mineral adalah memiliki kekuatan dielektriknya di atas 40 $\mathrm{kV}$. Berat jenisnya adalah 1.56 dan jika dicampur dengan air, minyak isolasi berada di bawah permukaan air sehingga mempermudah dalam proses pemurnian dan pemisahan kadar air dalam minyak. Pada kondisi pemakaian yang sama dengan minyak mineral, uap lembab akan menyebabkan oksidasi yang berlebih serta penurunan kekuatan dielektrik lebih cepat pada minyak sintetis bila dibandingkan dengan minyak mineral.

\section{Minyak Nilam}

Minyak nilam adalah minyak yang diperoleh dengan cara penyulingan uap daun tanaman Pogostemon Cablin BETNH (Dewan Standarisasi Nasional,1998). Standar mutu minyak nilam belum seragam belum seragam untuk seluruh 
Jambura Journal of Electrical and Electronics Engineering (JJEEE)

dunia, karena setiap negara penghasil dan pengekspor menentukan standar mutu minyak nilam sendiri, misalnya standar mutu minyak nilam dari indonesia (SNI 06-2385-1998) Spesifikasi minyak nilam :

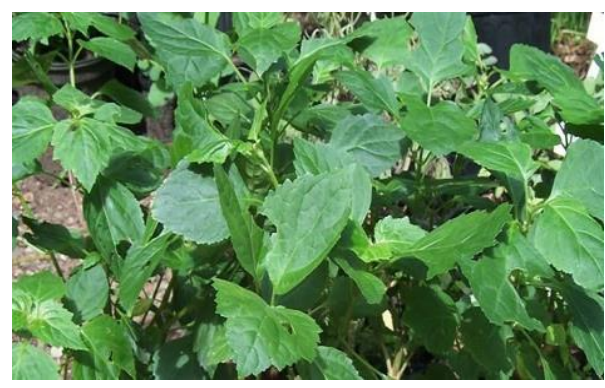

Gambar 1 tumbuhan Nilam

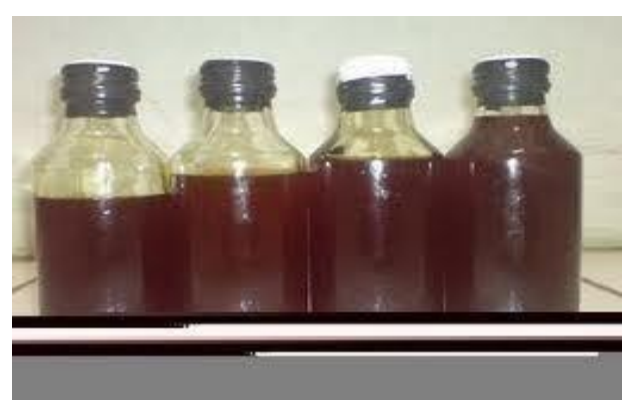

Gambar 2 Minyak Nilam

Tabel 1. Spesifikasi Syarat Mutu Minyak Nilam Menurut SNI 06-2388-2006

\begin{tabular}{|c|c|c|c|}
\hline No & Jenis Uji & Satuan & Persyaratan \\
\hline 1 & Wama & - & Kuning Muda -Coklat Tua \\
\hline 2 & Bobot Jenis $25^{\circ} \mathrm{C} / 25^{\circ} \mathrm{C}$ & - & $0,950-0,975$ \\
\hline 3 & Indeks bias $\left(\mathrm{nD}^{20}\right)$ & - & $1,507-1,505$ \\
\hline 4 & $\begin{array}{c}\text { Kelarutan dalam etanol } 90 \% \\
\text { pada suhu } 20^{\circ} \mathrm{C} \pm 3^{\circ} \mathrm{C}\end{array}$ & - & $\begin{array}{c}\text { Larutan jemih atau opalesensi } \\
\text { ringan dalam perbandingan } \\
\text { volume } 1: 10\end{array}$ \\
\hline 5 & Bilangan asam & - & Maks 8 \\
\hline 6 & Bilangan Ester & - & Maks 20 \\
\hline 7 & Putaran optik & - & $(-) 48^{\circ}-(-) 65^{\circ}$ \\
\hline 8 & Patchouli alcohol $\left(\mathrm{C}_{15} \mathrm{H}_{26} \mathrm{O}\right)$ & $\%$ & Min 30 \\
\hline 9 & Alpha copaene & $\%$ & Maks 0,5 \\
\hline 10 & Kandungan Besi & $\mathrm{mg} \mathrm{kg}$ & Maks, 25 \\
\hline
\end{tabular}

\section{Kandungan utama Minyak Nilam}

Minyak nilam terdiri dari persenyawaan terpen dengan alkohol alkohol, Aldehid dan ester - ester memberikan bau khas misalnya patchouli alkohol, patchouli alkohol merupakan senyawa yang menetukan bau minyak nilam dan merupakan komponen yang terbesar, komponen penyusun dari minyak nilam adalah benzaldehid, karyofilen, patchoulena, bulnesan dan patchouli alkohol (Ketaren, 1985).

\section{METODE PENELITIAN}

Peralatan Pengujian pada pengujian

\section{Tegangan Tembus}

- HV Trafo penaik tegangan, tegangan primer220 Volt, tegangan sekunder $100 \mathrm{kV}$, berfungsi untuk menaikkan tegangan dengan spesifikasi 1 fasa, 3 belitan, 220/100 kV, $5 \mathrm{kVA}, \mathrm{U}_{\mathrm{k}}=3,5 \%$ merk Terc



Gambar 3 HV Trafo

- Voltmeter Elektrostatik yang berfungsi sebagai alat ukur tegangan tembus yang terletak pada control desk 


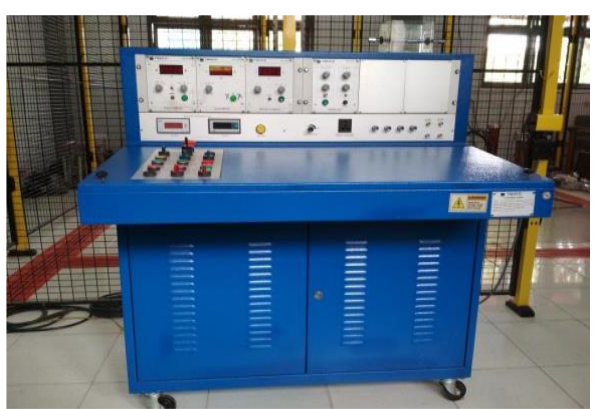

Gambar 4 kontrol desk

- Pembagi Kapasitif (Kapasitor), yang befungsi untukpembagi tegangan pada standar tertentu, dengan spesifikasi 100 pF, $100 \mathrm{kV}$ merk Terco



Gambar 5 Pembagi Kapasitif

\section{Pengujian Tegangan Tembus}

Penelitian dimulai dengan mengatur jarak sela elektroda pada Gelas uji. Kemudian minyak dimasukan kedalam Gelas uji dan Gelas uji dipasang pada rangkaian pengujian. Temperatur dan tekanan udara pada ruangan pengujian dicatat untuk mengetahui keadaan ruangan pengujian. Tegangan pada Control Desk dinaikkan hingga mencapai terjadi tembus listrik pada isolasi minyak yang ditandai dengan adanya loncatan api antara elektroda pada wadah uji dan diulang sebanyak 16 kali dengan jeda waktu setiap pengujian selama 3 menit. Jarak sela elektroda dan proses penggantian isolasi minyak dilakukan dengan cara yang sudah dijelaskan pada prosedur-prosedur sebelumnya. Setiap tegangan tembus dicatat sesuai dengan yang terlihat pada AC voltmeter Control Desk.

\section{Peralatan Pengujian Sifat Fisik Dan Kimia}

a. Peralatan yang digunakan pada pengujian kadar asam

- Buret

- Pemanas air

- Gelas ukur

- Alkohol 95\% netral

- Larutan KOH $0.1 \mathrm{~N}$

- Indikator fenoltalein

b. Peralatan yang digunakan pada pengujian kadar air

- Oven

- Cawan

c. Peralatan yang digunakan pada pengujian viskositas (sifat Kimi)

- Viskometer dan gelas Kimia

\section{HASIL PENELITIAN}

\section{Hasil pengujian tegangan tembus pada Minyak Nilam.}

Adapun data hasil pengujian tegangan tembus pada minyak Nilam menggunakan elektroda setengah bola 
dengan jarak 2,5 $\mathrm{mm}$ adalah sebagai berikut.

Tabel 1 Tegangan tembus minyak Minyak Nilam menggunakan Elektroda setengah bola.

Tabel 1 Pengujian Tegangan tembus

\begin{tabular}{|c|c|}
\hline \multirow{2}{*}{ Pengujian } & $\begin{array}{c}\text { Tegangan Tembus } \\
(\mathbf{k V})\end{array}$ \\
\cline { 2 - 2 } & Hasil Pengujian (kV) \\
\hline 1 & 9,16 \\
\hline 2 & 14,94 \\
\hline 3 & 15,58 \\
\hline 4 & 23,88 \\
\hline Rata - rata & 15,89 \\
\hline
\end{tabular}

Pada Tabel memperlihatkan hasil pengujian nilai tegangan tembus $(\mathrm{kV})$ minyak nilam dengan bentuk elektroda (setengah Bola) berdasarkan standar SPLN 49-1 Tahun 1982 dengan empat kali pengujian tegangan tembus, nilai tegangan tembus pada pengujian pertama tegangan tembus sebesar $9,16 \mathrm{kV}$, pengujian 2 sebesar 14,94 $\mathrm{kV}$, pengujian 3 nilai tegangan tembus 15,58 dan pengujian 4 nilai tegangan tembus adalah $15,89 \mathrm{kV}$.

Adapun nilai tegangan tembus dari minyak nilam sesuai dengan hasil pengujian semuanya belum memenuhi standar SPLN-1 tahun 1982 untuk tegangan tembus minyak isolasi pada transformator adalah $30 \mathrm{kV}$

\section{Hasil pengujian sifat fisik dan kimia minyak Nilam}

Pada pegujian viskositas ini dilakukan dengan menggunakan alat viskometer digital, hasil dari pengujian viskositas ini dapat dilihat langsung pada viskometer. Sedangkan untuk pengujian kadar Air dan kadar asam dilakukan dengan cara pengujian manual menggunakan beberapa persamaan. Dari hasil pengujian viskositas, kadar air, kadar asam dapat kita lihat pada tabel :

Tabel 2 Hasil pengujian kadar asam

\begin{tabular}{|c|c|c|}
\hline Perlakuan & Hasil analisis & Satuan \\
\hline 1 & 3,5532 & $\%$ \\
\hline 2 & 3,525 & $\%$ \\
\hline 3 & 3,525 & $\%$ \\
\hline
\end{tabular}

Tabel 3 Tabel Hasil pengujian kadar Air

\begin{tabular}{|c|c|c|}
\hline Perlakuan & Hasil analisis & Satuan \\
\hline 1 & 5,8694 & $\%$ \\
\hline 2 & 5,8694 & $\%$ \\
\hline 3 & 5,8688 & $\%$ \\
\hline
\end{tabular}

Tabel 4 Hasil pengujian viskositas

\begin{tabular}{|c|c|c|}
\hline Sampel & Suhu & Viskositas \\
\hline Minyak nilam & $40^{\circ} \mathrm{C}$ & $32 \mathrm{P}$ \\
\hline
\end{tabular}

\section{Analisis Pengujian Kadar Asam}

Pada pengujian kadar asam dilakukan sebanyak 3 kali agar hasil yang diperoleh lebih tepat. Hasil Pengujian kadar asam yang diperoleh masih dalam satuan persen. Oleh karena itu, harus di konversi ke dalam satuan mg $\mathrm{KOH} / \mathrm{kg}$.

- Percobaan $1=3,5532 \%$ x $10 \mathrm{gr}$

$$
=\frac{0,35532 \mathrm{gr} \mathrm{KOH}}{10 \mathrm{gr}}
$$




$$
\begin{aligned}
& =\frac{0,3552 \mathrm{gr}}{\frac{10}{1000}} \\
& =35,532 \mathrm{gr} \mathrm{KOH} / \mathrm{kg} \\
& =35.532 \mathrm{mg} \mathrm{KOH} / \mathrm{kg}
\end{aligned}
$$

- Percobaan $2=3,525 \%$ x 10 gr

$$
\begin{aligned}
& =\frac{0,3525 \mathrm{gr} \mathrm{KOH}}{10 \mathrm{gr}} \\
& =\frac{0,3525 \mathrm{gr}}{\frac{10}{1000}} \\
& =35,25 \mathrm{gr} \mathrm{KOH} / \mathrm{kg} \\
& =35.250 \mathrm{mg} \mathrm{KOH} / \mathrm{kg}
\end{aligned}
$$

- Percobaan $2=3,525 \%$ x 10 gr

$$
\begin{aligned}
& =\frac{0,3525 \mathrm{gr} \mathrm{KOH}}{10 \mathrm{gr}} \\
& =\frac{0,3525 \mathrm{gr}}{\frac{10}{1000}} \\
& =35,25 \mathrm{gr} \mathrm{KOH} / \mathrm{kg} \\
& =35.250 \mathrm{mg} \mathrm{KOH} / \mathrm{kg}
\end{aligned}
$$

Tabel 5 Pengujian Kadar Asam

\begin{tabular}{|c|l|l|l|}
\hline Perlakuan & $\begin{array}{l}\text { Berat } \\
\text { Sampel }\end{array}$ & $\begin{array}{l}\text { Kadar } \\
\text { Asam } \\
(\boldsymbol{\%})\end{array}$ & $\begin{array}{l}\text { Kadar } \\
\text { Asam } \\
(\mathbf{m g} / \mathbf{k g})\end{array}$ \\
\hline 1 & 10 & 3.5532 & 35.532 \\
\hline 2 & 10 & 3.525 & 35.250 \\
\hline 3 & 10 & 3.525 & 35.250 \\
\hline Rata-Rata & 10 & 3.5344 & 35.344 \\
\hline
\end{tabular}

Dari hasil analisis diperoleh bahwa rata - rata kadar asam minyak Nilam dengan tiga kali pengujian adalah 3.5344 (\%) atau $35.344(\mathrm{mg} / \mathrm{Kg})$

Standar kadar asam pada minyak trafo berdasarkan IEC 60296 - 2003 adalah $0,01 \mathrm{mg} / \mathrm{Kg}$. Berdasarkan hasil pada pengujian ini minyak Nilam belum memenuhi standar sebagai alternatif pengganti Minyak Trafo.

\section{Analisis Pengujian Kadar Air}

Pada pengujian kadar asam dilakukan sebanyak 3 kali agar hasil yang diperoleh lebih tepat. Hasil Pengujian kadar asam yang diperoleh masih dalam satuan persen. Oleh karena itu, harus di konversi ke dalam satuan $\mathrm{mg} / \mathrm{kg}$.

- Percobaan $1=5,8694 \%$ x 2 gr

$$
\begin{aligned}
& =\frac{0,117 \mathrm{gr}}{2 \mathrm{gr}} \\
& =\frac{0,117 \mathrm{gr}}{2 \mathrm{gr}} \times 1000 \\
& =58,5 \mathrm{gr} / \mathrm{kg} \\
& =58.500 \mathrm{mg} / \mathrm{kg}
\end{aligned}
$$

- Percobaan $2=5,8606 \%$ x 2 gr

$$
\begin{aligned}
& =\frac{0,1172 \mathrm{gr}}{2 \mathrm{gr}} \\
& =\frac{0,1172 \mathrm{gr}}{2 \mathrm{gr}} \times 1000 \\
& =58,6 \mathrm{gr} / \mathrm{kg} \\
& =58.60 \mathrm{mg} / \mathrm{kg}
\end{aligned}
$$

- Percobaan $3=5,8688 \%$ x 2 gr

$$
\begin{aligned}
& =\frac{0,1173 \mathrm{gr}}{2 \mathrm{gr}} \\
& =\frac{0,1173 \mathrm{gr}}{2 \mathrm{gr}} \times 1000 \\
& =58,68 \mathrm{gr} / \mathrm{kg} \\
& =58.688 \mathrm{mg} / \mathrm{kg}
\end{aligned}
$$


Jambura Journal of Electrical and Electronics Engineering (JJEEE)

\begin{tabular}{|c|c|c|c|}
\hline \multicolumn{4}{c}{ Tabel 6 Pengujian Kadar Air } \\
\hline \multirow{2}{*}{ Perlakuan } & $\begin{array}{c}\text { Berat } \\
\text { Sampel }\end{array}$ & $\begin{array}{c}\text { \% Kadar } \\
\text { Air }\end{array}$ & $\begin{array}{c}\text { Kadar } \\
\text { Air } \\
(\mathbf{m g} / \mathbf{K g})\end{array}$ \\
\hline 1 & 2 & 5,8694 & 58.500 \\
\hline 2 & 2 & 5,8606 & 58.60 \\
\hline 3 & 2 & 5,8688 & 58.688 \\
\hline Rata - rata & 2 & 5.86 & 58.596 \\
\hline Dari & hasil & \multicolumn{3}{c|}{ Pengujian } & diperoleh
\end{tabular}

bahwa rata-rata kadar air minyak Nilam untuk tiga kali perlakuan adalah 5,86 (\%) atau $58,596(\mathrm{mg} / \mathrm{Kg})$.

Standar kadar air untuk minyak trafo berdasarkan IEC 60296-2003 adalah 30 $\mathrm{mg} / \mathrm{Kg}$. Oleh karena itu dari sisi kadar air, minyak Nilam tidak memenuhi standar minyak trafo.

\section{Pengujian Viskositas}

Alat yang di gunakan pada pengujian viskositas adalah alat viskositas dinamis yaitu. Sedangkan yang nilai yang dibutuhkan adalah nilai viskositas kinematik. Oleh karena itu nilai viskositas dinamis yang diperoleh dari hasil pengujian menggunakan viskometer di konversi menjadi nilai viskositas kinematik yaitu dengan menggunakan persamaan berikut :

$$
\mathrm{V}=\frac{\mu}{\rho}
$$

V : Viskositas Kinematik (cSt)

$\mu$ : Viskositas Dinamis (cP)

$\rho$ : Massa Jenis Minyak Nilam $\left(\mathrm{g} / \mathrm{cm}^{3}\right)$

$$
\mu=0,32 \mathrm{cP}=0,32 \mathrm{P}=0,32 \mathrm{~g} /(\mathrm{cm} \mathrm{s})
$$

$$
\begin{aligned}
& \rho=0,965 \mathrm{~g} / \mathrm{cm} 3 \\
&>=\frac{0,32 \mathrm{~g} /(\mathrm{cm} \mathrm{s})}{0,965 \mathrm{~g} / \mathrm{cm}^{3}} \\
&=0,33116 \mathrm{~cm}^{2} / \mathrm{s} \\
&=33,16 \mathrm{~mm}^{2} / \mathrm{s} \\
&=33.16 \mathrm{cSt}
\end{aligned}
$$

Dari hasil pengujian diperoleh nilai Viskositas Minyak Nilam adalah 33.16 cSt.

Standar nilai viskositas untuk minyak trafo berdasarkan IEC 60296-2003 adalah 12 cSt. Oleh karena itu dari sisi viskositas (kekentalan), minyak Nilam tidak memenuhi standar Alternatif pengganti minyak trafo.

\section{KESIMPULAN}

Berdasarkan hasil penelitian terhadap karakterisik pengujian tegangan tembus dan pengujian karakteristik fisik dan kimia minyak nilam sebagai alternatif pengganti minyak Transformator diperoleh kesimpulan bahwa Pada minyak nilam ini jika di tinjau dari Pengujian karakteristik tegangan tembus dan karakteristik sifat fisik dan kimia belum memenuhi standar SPLN 49-1 Tahun 1982 dan standar IEC 60296- 2003 sebagai Alternatif pengganti minyak Trafo.

\section{SARAN}

Pada penelitian ini untuk pengujian tegangan tembus dan pengujian fisik dan 
kimia minyak nilam ini tidak layak dijadikan sebagai Alternatif pengganti minyak Transformator. Diharapkan pada penelitian selanjutnya dapat dilakukan pengujian dengan metode yang berbeda agar mendapatkan nilai parameter pengujian yang mendekati nilai standar.

\section{DAFTAR PUSTAKA}

[1] Agung prasetyo. (2015) “Analisis Tegangan Tembus Minyak Kelapa Sebagai Isolasi Cair Pada Variasi Elektroda Uji”,

[2] Asep Ahmad Ruri Irwanto. (2012) "Analisis Tegangan Tembus Minyak sawit (Palm Oil) Pada Tegangan Tinggi Bolak Balik Frekuensi Tenaga $50 \mathrm{~Hz} "$

[3] Badan Standarisasi Nasional. (2006) SNI 06-2385-2006 “Minyak Nilam” Jakarta: BSN

[4] Dwi Wulan Adharini. (2009) "budidaya dan penyulingan tanaman nilam aceh (pogostemon cablin benth) di deni nursery and gardening" Universitas Sebelas Maret Surakarta.

[5] Elia Krismiandaru dkk (2013) "uji tegangan tembus arus bolak-balik pada minyak jarak Sebagai alternatif isolasi cair" Universitas Diponegoro Semarang.

[6] Eko budiyanto. dkk. (2013), “Analisis Tegangan Tembus Minyak Kelapa
Murni (Virgin Coconut Oil) Sebagai isolasi cair Dengan Variasi Elektroda Uji” Universitas Diponegoro Semarang

[7] Harief Taufik Kurrahman \& Syamsir Abduh. (2016) "studi tegangan tembus minyak kemiri sunan sebagai alternatif pengganti minyak transformator daya”.

[8] Ketaren. (1985) “Pengantar teknologi miyak atsiri"

[9] Mangun, dkk (2008) "Nilam"

[10] Rudi Setiawan. (2017) "Perancangan Alat dan Pengujian Tegangan Tembus dengan Minyak Isolasi RBDPO Olein Menggunakan Elektroda Bola-Bola” Universitas Riau 